\title{
Entre o Deus e o Mundo: \\ Norma e desvio numa comunidade religiosa
}

\author{
Osvaldo de Assis Rocha Neto*
}

\begin{abstract}
Resumo: O artigo aborda o papel da Igreja Assembléia de Deus no cotidiano dos jovens da Cidade Estrutural, uma comunidade popular do Distrito Federal. O texto mostra como são construídas as normas que pautam as relações sociais dos integrantes da comunidade religiosa pesquisada e como estas mesmas normas são ressignificadas e constantemente renegociadas com o universo de valores dos jovens, o que acaba levando a produção de indivíduos ajustados e desviantes. Por fim o artigo mostra a reação dos líderes religiosos à forma como os valores da igreja são incorporados e ganham novos sentidos pelos jovens que negociam com um sistema de culpas e punições, instrumentos de socialização utilizados pela igreja para a educação religiosa dos jovens fiéis.
\end{abstract}

Palavras-chave: Juventude, Classes Populares, Religiáo e Comportamento Desviante

\begin{abstract}
The article approaches the role of the church Assembléia de Deus in the everyday life of the young people at Cidade Estrutural, a slum community of Distrito Federal. The text shows the construction of the rules that condition the social relation of the members of the religious community researched and how those same rules are re-signified and re-negotiated with the young people's universe of values which leads to adjusted and deviant behaviors. Finally the article reveals the reaction of the religious leaders about how the church values are incorporated and gain new meaning by the youngster that negotiate with a system of guilt and punishment, instruments of socialization used by the religious institution to educate the young believers.
\end{abstract}

Key words: Youth, Popular Classes, Religion and Deviant behavior

* Mestrando PPGSOL-UnB. E-mail: osvaldoassis@hotmail.com

Latitude, vol. 3, n², pp. 83-93, 2009

DOI: https://doi.org/10.28998/2179-5428.20090205 
Entre o Deus e o Mundo: Norma e desvio numa comunidade religiosa

\section{Entre o Deus e o Mundo: Norma e desvio numa comunidade religiosa}

O presente artigo tem por objetivo abordar o tema do comportamento desviante no interior de uma comunidade religiosa na Cidade Estrutural. Localizada na periferia de Brasília, a Estrutural é fruto de invasões de terras por parte de populações de baixa renda que migravam pelo Distrito Federal devido aos altos preços de aluguéis e viram na nova invasão a possibilidade da casa própria. A igreja em referência é uma igreja evangélica bastante tradicional que exerce um forte controle em seus fiéis, a Assembléia de Deus.

Pretendo aqui analisar a produção do desviante dentro do grupo de jovens da igreja Assembléia de Deus da Cidade Estrutural, a partir de um inventário de situações consideradas como desvio frente a doutrina dominante da igreja em questão que procura circunscrever a vontade dos fiéis. Para tanto, não perderemos de vista o proselitismo e os procedimentos utilizados pela igreja na lida com esses membros classificados e acusados de desviantes. Procurar-se-á apresentar os mecanismos de produção do desviante, o que os leva a infringir expectativas e regras que desencadeiam novas expectativas não correspondentes ao grupo. Aqui, como nos lembra Goffman, há uma discrepância entre a identidade real e virtual ou esperada percebida e que pode desembocar em uma situação de estigma por parte daqueles que passam por tal processo.

Só é possível falarmos de desvio a partir do momento que se institui a regra, Howard Becker, polemizando com a teoria funcionalista e sua rigidez em relação aos comportamentos desviantes afirma que:

"Tal premissa parece ignorar o fato primordial sobre o comportamento desviante: é criado pela sociedade. Não quero dizer com isso no sentido normalmente compreendido, em que as causas do desvio são localizadas na situação social do desviante ou em 'fatores sociais' que condicionam o seu comportamento. Quero dizer que os grupos sociais criam o desvio ao estabelecer as regras cuja infração constitui desvio e ao aplicá-las a pessoas particulares, marcando-as como outsiders. Sob tal pondo de vista, o desvio não é uma qualidade do ato que a pessoa faz, mas sim a conseqüência da aplicação por outrem de regras e sanções ao 'transgressor'. O desviante é aquele a quem tal marca foi aplicada com sucesso, o comportamento desviante é o comportamento assim definido por pessoas concretas." (Becker, 1966, pp. 8-9). 
Ou seja, a regra cria o desviante, uma vez que foi feita para que não seja infringida. Em se tratando de uma comunidade religiosa, a construção das regras se dá a partir de uma determinada leitura que realizam do mundo ancoradas ao que está na bíblia e no guia que esta oferece para a conduta de quem se dispõem a viver uma vida servindo a Deus. Este guia é o principal propulsor na orientação das ações daqueles que nele buscam amparo. Basta vermos os dez mandamentos entregues a Moisés ou mesmo a vida levada por Cristo como exemplos dentre tantos outros encontrados nesse livro de maneiras de se agir e fazer, de conformação de um habitus, para ficarmos numa linguagem bourdieusiana, voltado para uma vida na qual suas disposições e práticas estarão condicionadas dentro das diretrizes bíblicas.

A linguagem bíblica, seja pautada no novo ou antigo testamento, traça as linhas mestras do cristianismo que conformam o habitus das religiões cristãs ${ }^{1}$. Essas religiões buscam inspiração na Bíblia para estabelecerem as doutrinas as quais estarão submetidos os seus fiéis. Uma igreja como a Assembléia de Deus realiza uma leitura da bíblia extremamente rigorosa, é considerada uma das igrejas evangélicas brasileiras mais tradicionais do ponto de vista doutrinário. Fazem uma leitura do como agir e fazer cotidianos sem muita margem para a negociação e possibilidades diversas de se apresentar, onde a doutrina da igreja dificilmente é contestada, até porque há uma crença generalizada de seus fiéis que estas regras vieram diretamente de Deus e o que resta a fazer é respeitá-las.

No caso da igreja Assembléia de Deus da Cidade Estrutural aqui analisada essa assertiva não se mostra diferente, esta leitura de mundo é vivenciada a partir daquilo que retiram de ensinamentos de Deus e que a bíblia oferece. Não cabe aqui apontar todos os elementos que conformam a doutrina da igreja Assembléia de Deus, mas iremos recorrer a essa doutrina na medida em que formos descrevendo alguns atos tidos como desviantes de seus fiéis. O desviante aqui só é possível surgir a partir do momento que se cria uma regra passível de infração por algum indivíduo.

No caso em questão, a pergunta a respeito de quem estabelece as regras é facilmente respondível, uma vez que estamos diante de um caso de regra instituída por uma tradição religiosa e ancorada numa doutrina cristã que tem como alicerce a bíblia e suas versões do antigo e novo testamentos. Tal regra é pautada pela tradição e dificilmente é contestada por aqueles que seguem a religião que nelas se

\footnotetext{
${ }^{1}$ Habitus entendido aqui tal qual nos propõe Bourdieu (1998, 2000 e 2002), como um sistema de disposições duradouras de práticas que organiza e designa uma maneira de ser e de fazer em especial do corpo. São "estruturas estruturadas predispostas a funcionarem como tal, ou seja, enquanto princípio de geração e de estruturação de práticas e de representações que podem ser objetivamente reguladas e regulares sem em nada serem o produto da obediência a regras, objetivamente adaptadas ao seu fim sem suporem a mira consciente dos fins e o domínio expresso das operações necessárias para atingi-los, e sendo tudo isso, coletivamente orquestradas sem serem o produto da ação organizadora de um maestro de orquestra". p.163-4.
} 
Entre o Deus e o Mundo: Norma e desvio numa comunidade religiosa

ancora. Porém, se a pergunta a respeito dos produtores de regras não cabe para o caso de uma religião, como aponta Becker (1963) para outros casos cabe perguntarmos para a análise desta comunidade religiosa a respeito do que leva uma pessoa que se diz seguidora de tais regras a infringi-las. Ou seja, o que leva um indivíduo temente a Deus a agir em desconformidade com o seu habitus religioso.

Durante nosso trabalho de campo realizado junto a Igreja Assembléia de Deus - Ministério Guanabara da Cidade Estrutural, ficamos seis meses acompanhando os encontros do grupo de jovens dessa igreja, os cultos, sermões, retiros e festas numa tentativa de entender o processo de socialização e formação desse habitus religioso, um saber que thes é incorporado paulatinamente e repetidamente de forma que estes acabem apresentando uma educação corpórea em conformidade com o que lhes são ensinados. Pude presenciar o processo de produção desse habitus religioso, que desemboca numa educação e disciplina para com aquilo que é ensinado e que resulta em um processo eficiente de internalização da doutrina religiosa, fato que mostrou pouquíssimos casos de jovens que ficaram de prova durante o período pesquisado².

Porém, antes de falarmos dos casos de desvio dentro da igreja em questão é preciso mostrarmos como se dá a construção de um desviante típico nessa comunidade religiosa. Pode-se dizer que a categoria de desviante para a igreja se faz sempre em referência ao que eles denominam de mundo. O mundo seria tudo aquilo que se encontra fora da igreja, ou pra ser mais preciso, fora de uma vida que esteja em desacordo com as vontades de Deus. Ou seja, é preciso acreditar em Deus e praticar sua palavra mediante aquilo que a bíblia diz. A todo o momento, nas reuniões de jovens, nos cultos, nos sermões encontrávamos referências de como o mundo lida com algumas questões e como um cristão temente a Deus deve agir em tais situações. Nesse sentido, o que os integrantes da igreja chamam de mundo se apresenta como uma das pilastras do discurso da igreja. Este se torna o seu sistema de referências, um padrão de comparação com o qual se estabelece um diálogo no qual são deferidos sérios ataques ao modo como este mundo lida com algumas questões a exemplo do aborto, violência e educação.

Sob essa perspectiva eu era tido como um desviante. Apresentei-me à igreja deixando claras as minhas intenções de pesquisa. Porém, uma das primeiras perguntas que faziam era qual igreja eu freqüentava. Afirmava sempre que tive uma educação católica e que há tempos não freqüentava igrejas, já havia ido a muitas. Esse relato me colocava numa condição de convertível. Inúmeras foram as vezes em que fui submetido a pregação e a conselhos para que eu freqüentasse a igreja por parte dos jovens, obreiros e pastores.

Aqui vemos que a igreja só se faz em referência ao mundo, é o mundo que permite a construção do discurso da norma. Mas essa é uma relação que porta uma

${ }^{2} \mathrm{O}$ termo ficar de prova é uma categoria nativa que aparecia sempre que se referia a alguma pessoa que tinha andado em desacordo com as regras da igreja e que estava passando por uma espécie de punição pelo ato cometido. O termo será mais explorado adiante. 
forte ambigüidade, pois ao mesmo tempo em que a igreja precisa do mundo para legitimar seu discurso, apresentando as benesses de se estar dentro dela, essa mesma igreja não existiria sem o mundo. Este que permite que ela se mostre e tente impor um discurso de superioridade em relação ao que o mesmo mundo pode oferecer as pessoas. Porém, a mesma igreja empreende uma série de incursões no mundo no intuito de salvação, de retirar as pessoas da condição de pecadores de oferecê-las o reino dos céus ao convidá-las para terem uma vida para cristo. A ambigüidade encontra-se exatamente nesse quesito, pois ao mesmo tempo em que os desviantes são uma condição necessária fundamental para a existência da igreja e de seu discurso, essa mesma igreja tem o desejo e age em tal direção de angariar o maior numero de fiéis para engrossas as fileiras do exército de cristo. $O$ desviante de hoje é o servo de Deus de amanhã. Todos são passíveis de conversão, seja eu na minha condição de pesquisador ou os usuários e traficantes de droga.

O interessante notar é que as doutrinas da igreja foram feitas não no sentido deliberado de se construir um fiel tipicamente desviante. Dentro da comunidade religiosa em questão não há uma relação direta entre a criação da norma e a institucionalização do desviante, nos moldes que Becker sugere em suas análises sobre músicos de Jazz e usuários de drogas. Pelo contrário, a maioria das diretrizes apontadas pela doutrina da igreja não possui dentro de seu corpo de membros pessoas que infringiram tais regras. Um exemplo claro é o valor e respeito que dão aos mandamentos da tabua de Moisés, os quais nenhum membro desrespeita.

Porém, como esse artigo visa mostrar, há casos de infração da doutrina religiosa por parte de jovens que compartilham da comunidade de valores da igreja em questão. Mesmo que estes jovens fiquem submetidos a um sistema de provas, a intenção da igreja não se dá no sentido de retirá-los ou segregá-los do convívio com os demais. O objetivo da igreja é empreender uma reeducação de seu habitus religioso no sentido de que se reintegre ao grupo. Ou seja, a prova viria em nome da coesão do grupo.

O desviante aqui seria o jovem ou adulto, que para Goffman não correspondem às expectativas que a igreja tem sobre ele, abrindo uma disjunção entre a identidade real e a virtual. (Goffman 1999) A igreja aqui é entendida como um corpo de normas e doutrinas que deve ser seguido de forma inconteste, pois foram leis dadas por Deus e não merecem o desrespeito nem mesmo que paire alguma dúvida sobre a natureza de tais normas.

Via de regra, não encontramos nenhuma diferença substancial entre os jovens que comentem algum ato desviante e os jovens que nunca o fizeram. Convivem juntos no cotidiano da igreja, seja tocando na banda da igreja, ou os eventos e festas promovidas e organizadas pela mesma. $\mathrm{O}$ ato desviante se apresenta apenas como uma questão da contingência, não é algo deliberado que realizam diariamente, e nem querem realizá-lo de forma contínua, além do fato de possuírem um forte sentimento de culpa que os leva a agirem quase sempre em conformidade com o que a doutrina estabelece.

O jovem Carlos é bastante ativo dentro da igreja, uns afirmam ser o melhor baterista que a igreja já teve. Com seus 22 anos é extremamente dedicada à igreja, para a qual dedica grande parte de seu tempo. Sempre se dispõe a ajudar em 
Entre o Deus e o Mundo: Norma e desvio numa comunidade religiosa

qualquer atividade com a qual a igreja se encontra engajada. Carlos se define como uma pessoa temente e serva de Deus que nunca se envolveu com brigas.

Certo dia, no entanto, o jovem é provocado por um conhecido (que não freqüenta igreja) na rua, afirmou que foi insultado verbalmente e isso resulta em uma briga entre os dois. Bastante chateado, Carlos vai a um dos inúmeros bares da Cidade e toma uma cerveja. Uma senhora que freqüenta a mesma igreja o vê no bar. Encaminha a noticia até o pastor, que chama Carlos para uma conversa. Este, por sua vez, justifica-se relatando o fato ocorrido. O pastor reúne o conselho da igreja e decide uma punição para Carlos não só pelo ato de estar bebendo em um bar, mas também pelo fato de ter se envolvido numa briga com uma pessoa do mundo. O jovem foi destituído de sua função de baterista da banda da igreja e proibido de cantar, orar e se levantar durante os cultos pelo período de um mês. Esta constitui uma espécie de morte espiritual para o sujeito, uma vez que o momento mais esperado na igreja são os cultos. O jovem aceitou, admitiu que errou, e acabou pagando a prova. Até hoje tenta voltar para a função da qual foi destituído.

A pena da prova varia de acordo com a infração que o indivíduo comete. Outro caso que tomei conhecimento no período em que estive realizando a pesquisa foi o de um casal de namorados que transaram e acabaram contando ao pastor o que haviam feito. Este, mais uma vez se reúne com o conselho de pastores e obreiros e em conjunto com o casal de namorados, dão uma série de conselhos aos jovens, os obrigam a marcar uma data para o casamento além de estabelecerem uma punição aos dois. $\mathrm{O}$ jovem Marcos não mais cantou durante seis meses no coral da Igreja. A jovem Juliana, não mais saiu para a evangelização de outros jovens da cidade. Além da morte espiritual que também foi aplicada ao jovem Carlos, o prazo foi de 6 meses. Estes jovens passaram a exercer uma nova função na igreja com o casamento. O homem vai para o conselho de varões e a mulher para conselho de mulheres. Suas idades são, respectivamente, 17 e 19 anos.

Aqui podemos tecer alguns comentários sobre o forte controle que a igreja exerce sobre os fiéis. No plano da vigilância de uns pelos outros, a fofoca se mostra como um excelente instrumento de controle social nos moldes que Elias aponta em seu estabelecidos e outsiders. Os responsáveis por fazer valer a doutrina da igreja são os pastores e obreiros. Estes contam com os fiéis da igreja que os colocam a par do dia a dia dos membros. Caso percebam algo errado, de pronto se disponibilizam a conversar com aqueles que apresentaram algum problema. É uma invasão que o universo religioso realiza no universo da intimidde das pessoas, controlando as atitudes de cunho mais pessoal dos indivíduos. O mesmo ocorre quando percebem que algum membro da igreja se encontra afastado. Formam uma junta de cinco ou seis membros e vão até a casa desse irmão para saber se há algo errado e realizam orações. Este geralmente volta a freqüentar a igreja.

Outra questão a que os infratores estão sujeitos são os comentários constantes na igreja, principalmente durante os cultos, quando a pessoa não se manifesta. Este é o momento em que se publiciza a sua condição de desviante, o indicativo que realizou alguma coisa errada. Um dos membros faz comentários do tipo: ele ta de prova e o interlocutor complementa: você não sabia o que aconteceu... O exemplo apresentado indica que o individuo torna-se alvo de comentários de todos 
os integrantes da igreja, corroborando para desenhar uma imagem negativa dessa pessoa, que passa a conviver com um estigma na acepção de Goffman, (1988).

O conteúdo das aulas de catequese e das reuniões dos grupos de jovens tenta dialogar com essas questões estabelecendo fronteiras entre o que é certo e que é errado e formas de se resistir a tentações mundanas como a masturbação e o sexo antes do casamento. Esses são assuntos debatidos nas reuniões de jovens. A coordenadora do grupo, Isabel, sempre atenta para essas questões nas reuniões e leituras que realizam nos encontros semanais. Para as mulheres, afirma que a tentação é grande e que se deve evitar o contato mais forte porque senão fica mais difícil controlá-la; direcionada aos homens, fala para que estes ajam como cristãos respeitando as meninas e esperando a hora certa para se fazer "essas coisas".

Em todos os casos de infração da doutrina estabelecida pela igreja há uma punição para os desviantes que acaba ficando com uma imagem negativa frente aos demais membros da igreja, que vivem uma situação de estigmatizado em relação a seus pares. Esse indivíduo passa a personificar-se na punição que ele recebeu daqueles responsáveis pela aplicação da pena, no caso os pastores e obreiros. (Goffman, 1988)

Aos jovens e adultos que passam pelo sistema de provas faz-se necessário passarem por aulas de uma espécie de reeducação religiosa. Os batizados possuem um status maior na igreja, definidos quanto ao agir, servem de inspiração para os demais. Ao agirem em contradição com a doutrina da igreja passam por uma ressocialização religiosa, a qual sofrem muitos dos novos convertidos que chegam à igreja pelo mecanismo de evangelização. Nesse caso, ocorre uma perda significativa de status por parte dessas pessoas.

Certa vez, conversando com uma jovem da igreja que já havia ficado, tempo atrás, de prova em função dos beijos mais fortes que andava trocando com o namorado eu a indaguei sobre o motivo de não manter segredo frente aos pastores e obreiros e ela respondeu que quando está ciente que realizou algum ato tido como errado e vai para a igreja e tenta orar pra Deus, "é como se minha oração só chegasse até o teto e voltasse, eu não consigo, ai tenho que contar para o pastor, e isso não ocorre só comigo não". Este caso exemplifica um sentimento de culpa fortemente internalizado.

Muitos jovens acabam descarregando as coisas erradas que fizeram confidenciado-as para Isabel, a líder do grupo. Esta, por sua vez, procura resolver internamente. Porém, quando não consegue, ela recorre aos pastores. Os conselhos e ensinamentos dados por Isabel a respeito de questões como a sexualidade e desejos libidinosos são baseados em sua própria experiência: "eu já fui do mundo e sei como é. Não é fácil pra agüentar certas tentações não, então é mais fácil a gente falar aqui abertamente sobre isso pra depois não chegar novidade por aqui". Porém essa atitude não é repetida pelos pastores e obreiros que constantemente a repreende pela forma como leva o grupo de jovens, cobram mais rigidez por parte de Isabel.

Uma série de outros tipos de desvio que pude observar na igreja não mereceu punições tão graves, apenas uma ou outra chamada de atenção. Vestir a saia um pouco mais curta, ou o batom um pouco mais escuro ou mesmo o uso de bermuda e chinelos são exemplos. Geralmente esse tipo de desvio é cometido por jovens de menos idade, ou como eles mesmos se denominam de adolescentes até 
Entre o Deus e o Mundo: Norma e desvio numa comunidade religiosa

os seus 16 anos. São jovens que ainda não foram batizados nas águas e que estão incorporando ainda o seu habitus religioso. Por essa razão, há uma certa tolerância que os faz não serem submetidos às provas.

O caso em que a igreja tratou de forma mais dura um jovem desviante diz respeito a um homossexual, membro ativo da igreja (fazia parte da equipe de louvor, era vocalista da banda da igreja e filho de um dos membros mais antigos). Era bastante querido por todos até descobrirem e tecerem comentários do tipo, ele gosta de menino, até ficou com ou outro aqui da cidade já queria ficar com um menino da igreja também. Perguntei para mais de um jovem se eles tinham preconceito em relação a esse jovem chamado Alberto, a resposta que se ouvia continha o mesmo conteúdo: Deus não aprova ele ser assim não. Outros elaboravam um pouco mais o discurso dizendo que deus fez o homem para a mulher e a mulher para o homem. Inclusive, citavam passavam passagens bíblicas.

A questão é que quando chegou aos ouvidos do pastor o caso do jovem homossexual, esse de pronto veio conversar com o jovem Alberto perguntando se havia algo errado com ele e o jovem negou. $\mathrm{O}$ pastor, então, perguntou se era verdade que ele gostava mesmo era de homens e Alberto disse que sim. O pastor falou que era preciso que ele virasse homem, gostasse de mulher para poder seguir freqüentando a igreja, pois deus não aprovava tal atitude.

$\mathrm{O}$ mais interessante era a retórica do jovem, que procurava argumentos religiosos para se mostrar que não estava errado ser homossexual. Segundo Alberto, Deus ama a todos de forma igual sem distinção, não priva ninguém de ter fé, de orar e cantar porque é diferente dos demais. Alberto declarou a mim que adoraria continuar na igreja, que esta era a sua vida, seus amigos estavam lá, tinha muito em tudo aquilo. Porém, a condição para continuar ali, nas palavras do pastor e do conselho, era que ele virasse homem e gostasse de menina para ser um jovem normal como qualquer outro. O jovem não convenceu o conselho de pastores e obreiros e acabou saindo da igreja, mesmo a contragosto.

A igreja e a religião possuem um caráter ambíguo na Cidade Estrutural. Propõe integrar o jovem do mundo, oferecendo inúmeras opções que a cidade não oferece em função de sua carência de locais destinados ao lazer e a ocupação. Apresenta-se como algo imprescindível na vida desses jovens, uma alternativa viável, mostrando ser uma instituição altamente plural, tolerante e com respeito às diferenças. Neste caso, ela se assemelha ao movimento observado por Carvalho da pluralidade que o universo religioso vem apresentando nos últimos anos. (Carvalho, 1991)

No entanto, a partir do momento que esses jovens optam por freqüentar a igreja, que até então eram do mundo, praticava e conjugava valores mundanos, se submetem às mesmas regras rígidas as quais compartilham os jovens que estão na igreja há mais tempo. É interessante notar que todos os casos aqui vistos como desvio dentro da igreja partiram de pessoas que "nasceram na igreja", e não dos novos convertidos, de origem mundana. Estes, por sua vez, mostraram uma disciplina muito maior que os jovens das igrejas.

Na contramão da pluralidade que citamos no parágrafo anterior, a outra faceta da contradição existente na igreja Assembléia de Deus se assenta no fato de que esta igreja possui normas extremamente rígidas a serem seguidas, não 
tolerando contestação das mesmas e aplicando severas punições àqueles que a infringem. Uma interpretação possível para tal atitude recorre à obra de Mary Douglas na tentativa de acompanhar o raciocínio que nos leva a afirmar que o ato de infringir uma doutrina da igreja é uma espécie de impureza da mais alta periculosidade, que pode colocar por terra toda a certeza em que se calca a fé, uma vez que esta não abre espaço para a dúvida pairar, dando um caráter inconteste à doutrina. Os pastores e obreiros são os responsáveis por difundir tal idéia, sem se preocupar em indagar a validade ou veracidade daquilo que é dado por Deus.

O ideal de pureza passa a ser perseguido ferozmente pela igreja, pois quanto mais transparente, mais ordenada, mais pura, mais limpa e clara seja a percepção do que se deve fazer e seguir, mais se adequa aos ideais de Deus. O ideal é praticar e viver a palavra que é dada pelo livro sagrado, sem dar margem para contestações da Palavra e da doutrina. A veemência com que se combate movimentos opostos se justifica sob esse ponto de vista em função da importância da doutrina, pois a fé se calca justamente no fato de não haver dúvidas, pois a dúvida seria o mesmo que duvidar da existência de Deus.

A persistência no desvio no interior da igreja seria o mesmo que assinar a conivência por parte daqueles responsáveis por zelar da continuidade da obra de Deus em sua comunidade religiosa de duvidas da existência do Senhor. O combate utilizando punições severas, destituindo as pessoas de sua identidade religiosa se mostra como uma reação à ameaça que estão representando de abalar as causas pétreas defendidas pela igreja, que são o alicerce do mundo religioso em que vivem. A conivência com a infração de algum aspecto dessa doutrina significava admitir a possibilidade da não existência de Deus, ou outras interpretações para a mesma. Isso ficou claro no caso do jovem homossexual, que foi levado a se retirar da igreja, pois colocava em xeque a interpretação que os aplicadores da norma possuíam acerca do mundo religioso.

Dessa forma, vimos a partir de um estudo de caso, que a questão religiosa pode nos levar para dois caminhos distintos. Podemos encontrar a convivência de uma enorme pluralidade e tolerância em algumas dimensões da vida, até mesmo a incorporação de pessoas para o seio da comunidade religiosa em questão que anteriormente eram traficantes ou usuários de drogas na cidade. Por outro lado, há um fechamento total para alguns temas no que se refere ao ponto de vista doutrinário da igreja.

Os temas que dizem respeito aos alicerces das diretrizes as quais se calcam a fé dessa comunidade religiosa não são abertos a negociações e não há maneira de se estabelecer um dialogo para uma outra interpretação das questões referentes a eles. Portanto, dificilmente há um movimento no sentido de transformação. A permanência na interpretação atual vem em nome da preservação dos seus idéias de pureza. Conversando com os pastores da igreja há muito tempo sobre essa questão, estes me disseram que já foi bem mais rígida a atitude da igreja, uns defendem a volta dos velhos tempos em que a babá eletrônica ainda não havia invadido as casas dos fiéis e a moda e maquiagem não tinha contaminado a cabeça das pessoas. Olhando sob essa perspectiva percebe-se um movimento, mesmo que lento

${ }^{3}$ o termo "babá eletrônica" refere-se à televisão. 
Entre o Deus e o Mundo: Norma e desvio numa comunidade religiosa

na direção de uma maior abertura e diálogo por parte dessa igreja que enfrenta uma forte resistência da tradição em que se agarram os defensores das atitudes mais conservadoras da igreja.

\section{Bibliografia}

ABRAMO, H. Wendel e Branco, Pedro P. Martoni. (orgs). Retratos da Juventude Brasileira: Análises de uma pesquisa nacional. São Paulo: Ed. Perseu Abramo, 2005.

BECKER, H.\& Michal M. Symbolic interaction and cultural studies. Univ Chicago Press, 1990.

BECKER, Howard Saul. Método de pesquisa em ciências sociais. 3. ed. SP Hucitec, 1997.

Schster, 1997. Outisiders. Studies in the sociology of deviance. Ed. Simon \& . Uma teoria da ação coletiva. Rio de Janeiro: Zahar, 1977.

BOURDIEU, P. O Poder Simbólico. Lisboa: DIFEL, 1989.

1998.

A economia das trocas simbólicas. $5^{\mathrm{a}}$ Ed. São Paulo, perspectiva, Esboço de uma teoria da prática. Oeiras, Celta. 2002.

CARDOSO, Ruth C L; Sampaio, Helena. Bibliografia sobre a juventude. São Paulo: Ed. Univ São Paulo, 1995.

CARVALHO, J. J. Características do Fenômeno Religioso na Sociedade Contemporânea, $1991 . \quad$ in $\quad$ Série Antropológica: http://www.unb.br/ics/dan/serieantro.htm Republicado em Maria Clara Burgemer (Org.) O Impacto da Modernidade Sobre a Religião, 133-196. São Paulo: Edições Loyola, 1992.

DOUGLAS, Mary. Pureza e perigo, Lisboa: Edições 70, [1991]. P. 213 . Witchcraft, confessions and accusations. Tavstock publis. 1970.

. Os Lele revisitados, 1987 acusações de feitiçaria à solta. Mana, Out 1999, vol.5, no.2, p.07-30., e na pagina: www.scielo.br

DUMONT, L. O Individualismo. Rio de janeiro: Rocco, 1985. p. 283

DURKHEIM, E. Da Divisão Social do Trabalho. São Paulo, Martins Fontes, 1995. 
EISENSTADT, S. N. De geração a geração. São Paulo, perspectiva, 1976.

ELIAS, Norbert; SCOTSON, John L. Os estabelecidos e os outsiders: sociologia das relações de poder a partir de uma pequena comunidade. Rio de Janeiro: J Zahar, 2000.

GOFFMAN, Erving. A Representação do eu na vida cotidiana. 4. ed. Petrópolis: Editora Vozes Ltda, 1989.

Estigma: notas sobre a manipulação da identidade deteriorada. 4. ed. Rio de janeiro: LTC, c1988. p. 158

MANNHEIM, Karl; Foracchi, M. M. Karl Mannheim: Sociologia. São Paulo: Ática, 1982.

MERTON, Robert King. Sociologia: Teoria e estrutura. São Paulo: Mestre Jou, 1970.

PARSONS, T. El sistema social. Madrid, Revista do Ocidente, 1966.

VELHO, G. Desvio e divergência: Uma critica da patologia social. 5. ed. RJ: Zahar, 1985. 